\title{
Claroideoglomus etunicatum and Pantoea dispersa significantly enhance growth and nutrition of broom grass
}

\author{
Nikhil Sai $\mathbf{N}^{1}$, Ashwin $\mathbf{R}^{1}$, Bagyaraj $\mathrm{DJ}^{{ }^{*}}$ and Venugopala Rao $\mathbf{R}^{2}$ \\ ${ }^{1}$ Centre for Natural Biological Resources and Community Development (CNBRCD), 41 RBI Colony, Anand Nagar, \\ Bangalore 560024, Karnataka, India \\ ${ }^{2}$ Laya Resource Centre, Yendada, Visakhapatnam 530045, Andhra Pradesh, India
}

Nikhil Sai N, Ashwin R, Bagyaraj DJ, Venugopala Rao R 2021 - Claroideoglomus etunicatum and Pantoea dispersa significantly enhance growth and nutrition of broom grass. Studies in Fungi 6(1), 327-333, Doi 10.5943/sif/6/1/23

\begin{abstract}
Broom grass (Thysanolaena maxima) is an evergreen non-timber forest produce species. This grass is now domesticated for cultivation by farmers. It is a multi-purpose grass providing mainly inflorescence used as brooms for cleaning every household and also fodder for cattle, fuel wood for cooking and thus enhance farmers income. An earlier pot culture study brought out that Claroideoglomus etunicatum as the best arbuscular mycorrhizal fungus (AMF) and Pantoea dispersa as the best plant growth promoting rhizobacteria (PGPR) for inoculating broom grass. In the present investigation, a pot culture experiment was conducted in glasshouse to study the effect of individual and combined inoculation of $C$. etunicatum and $P$. dispersa on the growth of broom grass. The plant height, stem girth, biovolume index, plant dry weight, major and minor nutrient concentrations were significantly higher in plants inoculated with $C$. etunicatum $+P$. dispersa compared to inoculation with either of them. It was concluded that dual inoculation with the two selected beneficial microorganisms is best for enhancing the growth and yield of broom grass which in turn will improve the livelihood of the farmers.
\end{abstract}

Keywords - Microbial consortia - Mycorrhiza symbiosis - Thysanolaena maxima

\section{Introduction}

Arbuscular mycorrhizal fungi (AMF) form symbiotic association with nearly $80 \%$ of the plants. Improved plant growth due to inoculation of soil with AMF has been demonstrated, especially under phosphorus (P) deficient conditions (Bagyaraj et al. 2015). The growth improvement is mainly because of enhanced uptake of diffusion-limited nutrients like $\mathrm{P}, \mathrm{Zn}, \mathrm{Cu}$, etc. AMF can also enhance tolerance to root pathogens and abiotic stresses such as drought and metal toxicity (Bagyaraj 2011, Mathimaran et al. 2017). It also has synergistic interactions with other beneficial soil microorganisms thereby enhance plant growth (Anuroopa \& Bagyaraj 2017, Sukeerthi et al. 2020).

Plant growth promoting rhizobacteria (PGPR) are another group of beneficial soil bacteria that stimulate plant growth either directly or indirectly. Direct mechanism involves improvement of nutrient availability to the plant by fixing atmospheric nitrogen, solubilizing insoluble phosphates and producing phytohormones. Indirect mechanisms involve reducing the susceptibility to soilborne plant pathogens through siderophore and hydrogen cyanide $(\mathrm{HCN})$ production and activating induced systemic resistance (ISR) (Hemlata et al. 2015). AMF interacting synergistically with PGPR in soil and enhancing plant growth compared to inoculation with either of them has been 
reported by earlier workers in crop plants (Hemlata \& Bagyaraj 2015, Thilagar et al. 2016, Raghu et al. 2020a, b).

Thysanolaena maxima popularly known as 'broom grass' or 'tiger grass' is an ever green non-timber forest produce species. It grows in tussocks with an average of 4 to 5 resembling foxtail and used as broom to clean the floor in every Indian household. The broom grass can be grown even on marginal lands, wastelands and jhum (slash and burn cultivation) fallow, which not only generates local employment but also its fibrous root system promotes the sustainable use of fragile and degraded lands (Nikhil et al. 2019a, b). This non-timber forest produce due to over exploitation from natural resource is becoming an endangered species and hence attempts are being made for domestication of the species. When domesticated/ cultivated the growth of broom grass is not as good as compared to its growth under natural forest conditions. The possibility of improving its growth through inoculation with beneficial microorganisms like AMF and PGPR was contemplated in the present study based on several earlier reports on other crops (Thilagar et al. 2014, Nikhil et al. 2019c).

In earlier studies we have screened separately and selected the best AMF Claroideoglomus etunicatum (Nikhil et al. 2019a) and the best PGPR Pantoea dispersa which improved the growth and nutrition of broom grass under glasshouse conditions (Nikhil et al. 2019b). The objective of the present glasshouse study was to evaluate the effect of combined inoculation of the selected AMF and PGPR as microbial consortia compared to single inoculation on the promotion of growth and nutrition of broom grass under glasshouse conditions.

\section{Materials \& methods}

The glasshouse experiment was conducted at Centre for Natural Biological Resources and

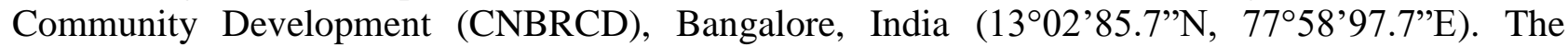
rhizome of broom grass used for planting in the present study was obtained from Laya Resource Centre, Vishakapatanam, Andhra Pradesh, India. The substrate used was soil:sand:compost in the ration 1:1:0.25 (v/v/v) respectively. Poly bags of the size $14 \times 26 \mathrm{~cm}$ were filled with $3.5 \mathrm{~kg}$ of the substrate. The substrate mix had a $\mathrm{pH}$ of 5.6 and $2.9 \mathrm{ppm}$ available $\mathrm{P}$ and an indigenous mycorrhizal population of 18 spores/ 10g of soil substrate (Nikhil et al. 2019c). AMF C. etunicatum maintained in the germplasm bank of CNBRCD, Bangalore using vermiculite mix (vermiculite: perlite: soilrite 3:1:1 v/v/v ratio) as the substrate and Rhodes grass (Chloris gayana) as the host was used in the experiment. The air-dried mix consisting of finely chopped root system plus substrate served as mycorrhizal inoculum. Pantoea dispersa grown on modified nutrient medium for $24 \mathrm{hrs}$ at $30^{\circ} \mathrm{C}$ which had population of $10^{8} \mathrm{cfu} / \mathrm{ml}$ was used as the inoculum.

A planting hole was made at the center of each polybag filled with the substrate. The different treatments used in the study were.

1. Uninoculated control

2. Inoculated only with C. etunicatum (C.et)

3. Inoculated only with $P$. dispersa (P.di)

4. Inoculated with C. etunicatum $+P$. dispersa (C.et+ P.di)

Three grams of mycorrhizal inoculum having 6,240 infective propagules (IP) per gram substrate were added to the planting holes depending on the treatment. Five ml of PGPR suspension was added to the planting holes based on the treatment. The polybags which did not receive microbial treatment acted as uninoculated control and received $3 \mathrm{~g}$ of vermiculite mix substrate and $5 \mathrm{ml}$ of modified NA media. Each treatment was replicated 12 times. Broom grass rhizome of uniform size were planted in poly bags. The plants were maintained in a glasshouse and watered whenever necessary.

Plants were harvested 7 months after planting. Plant height was measured from soil surface to the growing tip of the plant and stem girth was measured one $\mathrm{cm}$ above the soil surface using digital Vernier Calipers. Biovolume index (BI) (a measure of total volume of the plant) was determined using the formula given by Hatchell et al. (1985). The shoots and roots were separated and dried at $60^{\circ} \mathrm{C}$ in an oven to a constant weight to record the shoot and root dry weights. The 
dried samples were powdered and the nitrogen $(\mathrm{N})$ concentration of the shoot and root was estimated following the Microkjeldahl method (Jackson 1973). The shoot and root P concentration was estimated by vanadomolybdate phosphoric yellow colour method (Jackson 1973). The potassium (K) concentration was estimated by flame photometer method (Jackson 1973). The calcium $(\mathrm{Ca})$ and magnesium $(\mathrm{Mg})$ concentrations were estimated by EDTA titration method (Jackson 1973). The micronutrients $\mathrm{Zn}, \mathrm{Fe}, \mathrm{Cu}, \mathrm{Mn}$ and $\mathrm{Bo}$ in the plant was estimated by atomic absorption spectroscopy (AAS) using a hallow cathode lamp set to standard wavelengths (Aggarwal 2018).

Per cent mycorrhizal root colonization was determined after staining the root samples with trypan blue (Philips \& Hayman 1970). AM spore numbers in the root zone soil was estimated by wet sieving and decantation method (Gerdemann \& Nicolson 1963). P. dispersa population in the substrate was enumerated by the spread plate technique (Sanders 2012). Dehydrogenase activity of the root zone soil was determined following the procedure given by Casida et al. 1964). Statistical analysis of the data was done by analysis of variance (ANOVA) followed by Duncan's multiplerange test (DMRT) using statistical software AGRES version 3.01.

\section{Results}

Plant height in uninoculated plants was $26.3 \mathrm{~cm} /$ plant while in plants inoculated with C.et, P.di and C.et+P.di it was significantly more with values 31.0, 29.0 and $32.3 \mathrm{~cm} /$ plant respectively (Table 1). Stem diameter followed a similar trend. BI in uninoculated plants was 114.8. In plants inoculated with C.et and C.et+P.di it was 136.7 and 144.1 respectively differing significantly from uninoculated plants. Shoot dry weight in uninoculated plants was $16.6 \mathrm{~g} /$ plant, while in C.et, P.di and C.et+P.di inoculated plants it was 22.1, 20.8 and 25.7g/ plant respectively, all the three being significantly more compared to uninoculated plants. The root dry weight followed more or less a similar trend. Total plant dry weight of C.et, P.di and C.et+P.di inoculated plants were 32, 25 and $47 \%$ more compared to uninoculated plants with $25.8 \mathrm{~g} /$ plant. All the three values of inoculated plants were significantly higher compared to uninoculated plants (Table 1). N, P, K concentrations in shoot \& root of uninoculated plants was $0.89 \& 0.70,0.24 \& 0.09,2.02 \& 0.86 \%$ respectively. All the three inoculated treatments significantly increased the three major nutrient concentrations, the highest increase being recorded in dual inoculated plants. The increase due to dual inoculation in shoot \& root concentration of $\mathrm{N}$ was $12 \& 10 \%$; $\mathrm{P}$ was $29 \& 111 \%$ and $\mathrm{K}$ was $6 \& 86 \%$ (Table 2). Nutrient concentration of secondary nutrient $\mathrm{Ca}$ in shoot \& root and $\mathrm{Mg}$ in shoot followed a similar trend (Table 3).

The mycorrhizal root colonization in uninoculated plants was $51.3 \%$ while it was $90.7,69.3$ and $96.7 \%$ in C.et, P.di and C.et+P.di inoculated plants respectively, all the inoculated treatments differing significantly from the uninoculated treatment. Mycorrhizal spore numbers was significantly higher in C.et+P.di treatment with 431 spores $/ 50 \mathrm{~g}$ of substrate compared to all other inoculated and uninoculated treatments. The population of Pd was $85 \times 10^{5} / \mathrm{g}$ substrate in C.et+P.di inoculated treatment but was not differing significantly from Pd alone treatment. Other treatments had significantly lower Pd population in the substrate, the least being in uninoculated plants with $8.5 \times 10 \% \mathrm{~g}$ substrate. Dehydrogenase activity which indicates the abundance and activity of microorganisms in soil was 2578, 2150 and $2513 \mu \mathrm{g}$ of TPF released/ g of substrate/ hr in C.et+P.di, P.di and C.et respectively differing significantly from uninoculated treatment with $1975 \mu \mathrm{g}$ of TPF released/g of substrate/ hr (Table 4).

Table 1 Influence of microbial inoculants on plant growth parameters of broom grass

\begin{tabular}{lllllll}
\hline Treatments & $\begin{array}{l}\text { Height } \\
(\mathbf{c m} / \mathbf{p l a n t})\end{array}$ & $\begin{array}{l}\text { Stem } \\
\text { diameter } \\
(\mathbf{m m} / \mathbf{p l a n t})\end{array}$ & BI & $\begin{array}{l}\text { Shoot } \\
\text { dry weight } \\
\text { (g/ plant) }\end{array}$ & $\begin{array}{l}\text { Root dry } \\
\text { weight } \\
\text { (g/ plant) }\end{array}$ & $\begin{array}{l}\text { Total plant } \\
\text { dry weight } \\
\text { (g/ plant) }\end{array}$ \\
\hline $\begin{array}{l}\text { Uninoculated control } \\
\text { Claroideoglomus }\end{array}$ & $26.3^{\mathrm{c}}$ & $4.3^{\mathrm{b}}$ & $114.8^{\mathrm{b}}$ & $16.6^{\mathrm{c}}$ & $9.2^{\mathrm{b}}$ & $25.8^{\mathrm{c}}$ \\
etunicatum (C.et) & $31.0^{\mathrm{ab}}$ & $4.4^{\mathrm{a}}$ & $136.7^{\mathrm{a}}$ & $22.1^{\mathrm{b}}$ & $12.0^{\mathrm{a}}$ & $34.1^{\mathrm{b}}$ \\
\hline
\end{tabular}


Table 1 Continued.

\begin{tabular}{lllllll}
\hline Treatments & $\begin{array}{l}\text { Height } \\
(\mathbf{c m} / \mathbf{p l a n t})\end{array}$ & $\begin{array}{l}\text { Stem } \\
\text { diameter } \\
(\mathbf{m m} / \mathbf{p l a n t})\end{array}$ & BI & $\begin{array}{l}\text { Shoot } \\
\text { dry weight } \\
(\mathrm{g} / \text { plant })\end{array}$ & $\begin{array}{l}\text { Root dry } \\
\text { weight } \\
(\mathbf{g} / \text { plant })\end{array}$ & $\begin{array}{l}\text { Total plant } \\
\text { dry weight } \\
\text { (g/ plant })\end{array}$ \\
\hline $\begin{array}{l}\text { Pantoea dispersa } \\
\text { (P.di) }\end{array}$ & $29.0^{\mathrm{b}}$ & $4.4^{\mathrm{a}}$ & $128.9^{\mathrm{ab}}$ & $20.8^{\mathrm{b}}$ & $11.4^{\mathrm{ab}}$ & $32.2^{\mathrm{b}}$ \\
C.et+P.di & $32.3^{\mathrm{a}}$ & $4.4^{\mathrm{a}}$ & $144.1^{\mathrm{a}}$ & $25.7^{\mathrm{a}}$ & $12.2^{\mathrm{a}}$ & $37.9^{\mathrm{a}}$ \\
\hline SED & 1.28 & 0.22 & 9.93 & 1.23 & 0.94 & 1.53 \\
CD $(0.05)$ & 2.57 & 0.45 & 20.00 & 2.54 & 1.93 & 3.15 \\
\hline
\end{tabular}

Values superscripted with identical letters within each column do not differ significantly at $\mathrm{p} \leq 0.05$; $\mathrm{CD}$ :

Critical difference; UC: Uninoculated control; C.et: Claroideoglomus etunicatum; P.di: Pantoea dispersa

Table 2 Influence of microbial inoculants on major and secondary nutrient concentration (\%) of broom grass

\begin{tabular}{lllllllllll}
\hline \multirow{2}{*}{ Treatments } & $\mathbf{N}$ & \multicolumn{3}{c}{$\mathbf{P}$} & & $\mathbf{K}$ & \multicolumn{3}{c}{ Ca } & \multicolumn{3}{c}{ Mg } \\
\cline { 2 - 10 } & Shoot & Root & Shoot & Root & Shoot & Root & Shoot & Root & Shoot & Root \\
\hline UC & $0.89^{\mathrm{c}}$ & $0.70^{\mathrm{c}}$ & $0.24^{\mathrm{b}}$ & $0.09^{\mathrm{d}}$ & $2.02^{\mathrm{d}}$ & $0.86^{\mathrm{c}}$ & $0.67^{\mathrm{c}}$ & $0.34^{\mathrm{c}}$ & $0.22^{\mathrm{c}}$ & $0.12^{\mathrm{c}}$ \\
C.et & $0.95^{\mathrm{b}}$ & $0.75^{\mathrm{b}}$ & $0.29^{\mathrm{a}}$ & $0.15^{\mathrm{b}}$ & $2.09^{\mathrm{b}}$ & $1.51^{\mathrm{b}}$ & $0.76^{\mathrm{a}}$ & $0.58^{\mathrm{a}}$ & $0.26^{\mathrm{a}}$ & $0.14^{\mathrm{b}}$ \\
P.di & $1.00^{\mathrm{a}}$ & $0.75^{\mathrm{b}}$ & $0.26^{\mathrm{b}}$ & $0.11^{\mathrm{c}}$ & $2.06^{\mathrm{c}}$ & $1.50^{\mathrm{b}}$ & $0.73^{\mathrm{b}}$ & $0.52^{\mathrm{b}}$ & $0.24^{\mathrm{b}}$ & $0.12^{\mathrm{c}}$ \\
C.et+P.di & $1.00^{\mathrm{a}}$ & $0.77^{\mathrm{a}}$ & $0.31^{\mathrm{a}}$ & $0.19^{\mathrm{a}}$ & $2.13^{\mathrm{a}}$ & $1.60^{\mathrm{a}}$ & $0.77^{\mathrm{a}}$ & $0.58^{\mathrm{a}}$ & $0.27^{\mathrm{a}}$ & $0.24^{\mathrm{a}}$ \\
\hline SED & 0.002 & 0.01 & 0.009 & 0.01 & 0.007 & 2.35 & 0.008 & 0.01 & 0.008 & 0.01 \\
CD $(0.05)$ & 0.001 & 0.02 & 0.002 & 0.01 & 0.017 & 5.76 & 0.020 & 0.01 & 0.020 & 0.01 \\
\hline
\end{tabular}

Values superscripted with identical letters within each column do not differ significantly at $\mathrm{p} \leq 0.05$; CD:

Critical difference; UC: Uninoculated control; C.et: Claroideoglomus etunicatum; P.di: Pantoea dispersa

Table 3 Influence of microbial inoculants on minor nutrient concentration ( $\mathrm{ppm}$ ) of broom grass

\begin{tabular}{lllllllllllll}
\hline \multirow{2}{*}{ Treatments } & Zn & \multicolumn{3}{c}{ Fe } & \multicolumn{3}{c}{ Cu } & \multicolumn{3}{c}{ Mn } & \multicolumn{3}{c}{ B } & \multicolumn{3}{c}{ Mo } \\
\cline { 2 - 12 } & Shoot & Root & Shoot & Root & Shoot & Root & Shoot & Root & Shoot & Root & Shoot & Root \\
\hline UC & $42.4^{\mathrm{c}}$ & $30.2^{\mathrm{d}}$ & $371.1^{\mathrm{c}}$ & $174.4^{\mathrm{d}}$ & $26.9^{\mathrm{d}}$ & $37.7^{\mathrm{c}}$ & $22.8^{\mathrm{b}}$ & $9.3^{\mathrm{c}}$ & $18.2^{\mathrm{d}}$ & $7.5^{\mathrm{c}}$ & $7.6^{\mathrm{d}}$ & $43.1^{\mathrm{c}}$ \\
C.et & $63.7^{\mathrm{a}}$ & $62.6^{\mathrm{b}}$ & $495.3^{\mathrm{b}}$ & $276.3^{\mathrm{c}}$ & $34.7^{\mathrm{b}}$ & $58.4^{\mathrm{b}}$ & $31.3^{\mathrm{a}}$ & $17.1^{\mathrm{b}}$ & $22.9^{\mathrm{c}}$ & $11.9^{\mathrm{b}}$ & $14.5^{\mathrm{b}}$ & $72.0^{\mathrm{a}}$ \\
P.di & $53.3^{\mathrm{b}}$ & $49.6^{\mathrm{c}}$ & $501.9^{\mathrm{b}}$ & $304.1^{\mathrm{b}}$ & $31.4^{\mathrm{c}}$ & $56.3^{\mathrm{b}}$ & $31.4^{\mathrm{a}}$ & $14.2^{\mathrm{b}}$ & $29.0^{\mathrm{b}}$ & $15.7^{\mathrm{a}}$ & $11.5^{\mathrm{c}}$ & $62.7^{\mathrm{b}}$ \\
C.et+P.di & $65.6^{\mathrm{a}}$ & $73.5^{\mathrm{a}}$ & $646.6^{\mathrm{a}}$ & $327.6^{\mathrm{a}}$ & $52.6^{\mathrm{a}}$ & $142.0^{\mathrm{a}}$ & $31.4^{\mathrm{a}}$ & $52.0^{\mathrm{a}}$ & $35.1^{\mathrm{a}}$ & $16.4^{\mathrm{a}}$ & $22.8^{\mathrm{a}}$ & $79.3^{\mathrm{a}}$ \\
\hline SED & 0.82 & 3.78 & 6.42 & 3.46 & 0.41 & 3.10 & 0.71 & 1.31 & 0.01 & 0.61 & 0.01 & 3.01 \\
CD $(0.05)$ & 2.01 & 9.25 & 15.71 & 8.47 & 0.99 & 7.59 & 1.73 & 3.21 & 0.01 & 1.50 & 0.01 & 7.36 \\
\hline
\end{tabular}

Values superscripted with identical letters within each column do not differ significantly at $\mathrm{p} \leq 0.05$; CD:

Critical difference; UC: Uninoculated control; C.et: Claroideoglomus etunicatum; P.di: Pantoea dispersa

Table 4 Influence of microbial inoculants on microbial parameters of broom grass

\begin{tabular}{|c|c|c|c|c|}
\hline Treatments & $\begin{array}{l}\text { Mycorrhizal } \\
\text { root } \\
\text { colonization } \\
(\%)\end{array}$ & $\begin{array}{l}\text { Mycorrhizal } \\
\text { spore number/ } \\
50 \mathrm{~g} \text { of } \\
\text { substrate }\end{array}$ & $\begin{array}{l}\text { CFU of } \\
P . \text { dispersa } \\
\left(10^{5} / \mathrm{g}\right. \\
\text { substrate) }\end{array}$ & $\begin{array}{l}\text { Dehydrogenase } \\
\text { ( } \mu \text { g of TPF } \\
\text { released/g root } \\
\text { zone soil/ hr) }\end{array}$ \\
\hline Uninoculated control & $51.3^{\mathrm{c}}$ & $20.5^{\mathrm{d}}$ & $8.5^{\mathrm{b}}$ & $1975^{\mathrm{d}}$ \\
\hline Claroideoglomus etunicatum $(\mathrm{Ce})$ & $90.7^{\mathrm{a}}$ & $298.9^{\mathrm{b}}$ & $10^{\mathrm{b}}$ & $2512.5^{\mathrm{b}}$ \\
\hline Pantoea dispersa $(\mathrm{Pd})$ & $69.3^{\mathrm{b}}$ & $110^{\mathrm{c}}$ & $79^{\mathrm{a}}$ & $2150^{\mathrm{c}}$ \\
\hline $\mathrm{Ce}+\mathrm{Pd}$ & $96.7^{\mathrm{a}}$ & $430.6^{\mathrm{a}}$ & $85^{\mathrm{a}}$ & $2577.5^{\mathrm{a}}$ \\
\hline SED & 0.52 & 10.33 & 2.93 & 8.16 \\
\hline $\mathrm{CD}(0.05)$ & 1.06 & 21.16 & 6.75 & 18.82 \\
\hline
\end{tabular}

Values superscripted with identical letters within each column do not differ significantly at $\mathrm{p} \leq 0.05$; CD:

Critical difference; UC: Uninoculated control; C.et: Claroideoglomus etunicatum; P.di: Pantoea dispersa 


\section{Discussion}

The results of the present study show that inoculation with microbial consortia C.et+P.di significantly enhanced growth and nutrition of broom grass under glasshouse conditions. It has been reported earlier that inoculation with microbial consortia (AMF + PGPR) significantly enhance growth of crop plants like chilly, ashwagandha, and tomato (Thilagar et al. 2016, Anuroopa \& Bagyaraj 2017, Desai et al. 2019).

Plants inoculated with C.et+P.di significantly improved plant growth parameters like plant height and BI. Higher BI value indicates higher quality of plants which will also establish better when planted in the field (Hatchell et al. 1985). Increase in plant growth parameters due to inoculation with AMF + PGPR has been observed in other crops like acacia and teak (Raghu et al. 2020a, b). Increased shoot, root and total plant dry weight observed in the present study because of dual inoculation with selected AMF + PGPR is in conformity with such reports published earlier in other plants with selected AMF + PGPR (Ashwin et al. 2019, Jyothi \& Bagyaraj 2017).

The plants inoculated with C.et+P.di resulted in the uptake of most of the primary and secondary nutrients compared to singly inoculated and uninoculated plants. Significant increase in primary major nutrients ( $\mathrm{N}, \mathrm{P}$ and $\mathrm{K}$ ) and the secondary major nutrients ( $\mathrm{Ca}$ and $\mathrm{Mg}$ ) was observed in inoculated plants with microbial consortia. Increased $\mathrm{N}, \mathrm{P}$ and $\mathrm{K}$ uptake because of dual inoculation with AMF + PGPR has been reported in other crops by earlier workers (Adesemoye et al. 2008, Jyothi \& Bagyaraj 2017). Similarly increase in the secondary major nutrients $\mathrm{Ca}$ and $\mathrm{Mg}$ due to inoculation with microbial consortia with selected AMF + PGPR is in conformity with the earlier reports in corn (Adesemoye et al. 2008). Inoculation with C.et+P.di significantly enhanced minor nutrient concentration in both shoot and root compared to uninoculated control. Minor nutrients play a vital role for proper functioning of plant metabolism and regulating general plant growth. Earlier workers have reported that inoculation with AMF + PGPR enhances uptake of minor nutrients in flowering plants (Sukeerthi et al. 2020).

In the present study inoculating with microbial consortia significantly enhanced percent mycorrhizal root colonization and spore numbers in root zone soil compared to uninoculated plants which was evident from several works reported (Hemlata et al. 2015, Thilagar et al. 2016). Higher root colonization helps in better absorption of nutrients and hence better plant growth. PGPR population in substrate was found to be significantly higher in inoculated plants compared to uninoculated plants. This is in conformity with the results obtained earlier in tomato by Abhaya et al. (2019) and Desai et al. (2019). Dehydrogenase activity in soil is used as an indicator of microbial activity. In the present study dehydrogenase activity in the root zone soil was significantly higher in AMF+PGPR treatment compared to other inoculated and uninoculated treatments, supporting results obtained earlier by other workers in other crops. Similar results were observed in tulasi and tomato by earlier workers (Jyothi \& Bagyaraj 2017, Abhaya et al. 2019).

$\mathrm{AMF}$ is known to improve plant nutrition and protect the plants from biotic and abiotic stresses and there by promote plant growth (Jung et al. 2012, Begum et al. 2019). PGPR promote plant growth by production of phyto-hormones and protect plants against root pathogens (Hemlata et al. 2015). Synergistic interaction between AMF+PGPR is also well documented (Thilagar et al. 2016, Jyothi \& Bagyaraj 2017). Taking into consideration all the parameters studied and giving weightage to shoot and total plant dry weight, nutrient uptake and soil microbial activity it can be concluded that inoculation with the microbial consortia C.et+P.di significantly enhances the growth and nutrition of broom grass under glasshouse conditions. Validation of this glasshouse study under field conditions is in progress with initial positive indication. Thus, inoculation of broom grass with the eco-friendly and cost effective selected microbial consortia will be a profitable enterprise for the farming community in future.

\section{Acknowledgements}

This work was financed by SEED Division, Department of Science and Technology, GOI with File no. SP/TSP/007/2016. 


\section{References}

Abhaya DB, Nikhil N, Ashwin R, Bagyaraj D. 2019 - Influence of AM fungus G. mosseae and plant growth promoting rhizobacteria (PGPR) on growth of tomato seedlings raised in pro trays. Journal of Soil Biology and Ecology 39, 53-63.

Adesemoye AO, Torbert HA, Kloepper JW. 2008 - Enhanced plant nutrient use efficiency with PGPR and AMF in an integrated nutrient management system. Canadian journal of Microbiology 54, 876-886.

Aggarwal M. 2018 - Experiment-32 determination of copper, zinc, lead and cadmium in food products by atomic absorption spectroscopy. In: Aggarwal M (ed), Practical manual chemical analysis and quality assurance. IGNOU Publication, New Delhi, pp. 87-89.

Anuroopa N, Bagyaraj DJ. 2017 - Inoculation with selected microbial consortia enhanced the growth and yield of Withania somnifera under polyhouse conditions. Imperial Journal of Interdisciplinary Research 3, 127-133.

Ashwin R, Bagyaraj DJ, Mohan Raju B. 2019 - Symbiotic response of drought tolerant soybean varieties, DSR 2 and DSR 12 to different arbuscular mycorrhizal fungi. Proceedings of National Academy of Sciences India Section B Biological Sciences 89, 649-655.

Bagyaraj DJ. 2011 - Microbial biotechnology for sustainable agriculture, horticulture and forestry. New India Publishing Agency, New Delhi, India.

Bagyaraj DJ, Sharma MP, Maiti D. 2015 - Phosphorus nutrition of crops through arbuscular mycorrhizal fungi. Current Science 108, 1288-1293.

Begum N, Qin C, Ahanger MA, Raza S et al. 2019 - Role of arbuscular mycorrhizal fungi in plant growth regulation: implications in abiotic stress tolerance. Frontiers in Plant Science. Doi 10.3389/fpls.2019.01068

Casida L, Klein D, Santoro T. 1964 - Soil dehydrogenase activity. Soil Science 98, 371-376.

Desai S, Bagyaraj DJ, Ashwin R. 2020 - Inoculation with microbial consortia promotes growth of tomato and capsicum seedlings raised in pro trays. Proceedings of National Academy of Sciences India Section B Biological Sciences 90, 21-28.

Gerdemann JW, Nicolson TH. 1963 - Spores of mycorrhizal Endogone species extracted from soil by wet sieving and decanting. Transactions of the British Mycological Society. 46, 235-244.

Hatchell GE, Berry CR, Muse HD. 1985 - Nondestructive indices related to aboveground biomass of young loblolly and sand pines on ectomycorrhizal and fertilizer plots. Forest Science 31, 419-427.

Hemlata C, Bagyaraj DJ. 2015 - Inoculation with selected microbial consortia not only enhances growth and yield of French bean but also reduces fertilizer application under field condition. Scientia Horticulture 197, 441-446.

Hemlata C, Bagyaraj DJ, Selvakumar G, Sundaram SP. 2015 - Novel plant growth promoting rhizobacteria - Prospects and potential. Applied Soil Ecology 95, 38-53.

Jackson ML. 1973 - Soil chemical analysis. Prentice Hall (India) Pvt. Ltd. New Delhi, India.

Jung SC, Martinez-Medina A, Lopez-Raez JA, Pozo MJ. 2012 - Mycorrhiza-induced resistance and priming of plant defenses. Journal of Chemical Ecology 38, 651-664.

Jyothi E, Bagyaraj DJ. 2017 - Inoculation with microbial consortia enhances the growth, nutrition and oil concentration of Ocimum sanctum. Medicinal Plants - International Journal of Phytomedicines and Related Industries 9, 237-241.

Mathimaran N, Sharma MP, Mohan Raju B, Bagyaraj DJ. 2017 - Arbuscular mycorrhizal symbiosis and drought tolerance in crop plants. Mycosphere 8, 361-376.

Nikhil Sai N, Ashwin R, Bagyaraj DJ, Venugopala Rao R. 2019a - Selection of an Efficient Arbuscular Mycorrhizal Fungus for inoculating Broom Grass (Tysandaena maxima). KAVAKA 53, 8-11.

Nikhil Sai N, Ashwin R, Bagyaraj DJ, Venugopala Rao R. 2019b - Selection of an efficient plant growth promoting rhizobacteria for inoculating Broom grass (Thysanolaena maxima). Journal of Soil Biology and Ecology 39, 39-45. 
Nikhil N, Ashwin R, Harinikumar KM, Bagyaraj DJ. 2019c - Single inoculation with an AM fungus enhanced growth of Phyllanthus emblica compared to its co-inoculation with plant growth promoting rhizomicroorganisms. Studies in Fungi. 4, 244-252.

Philips JM, Hayman DS. 1970 - Improved procedures for clearing roots and staining parasitic and vesicular mycorrhizal fungi for rapid assessment of infection. Transactions of the British Mycological Society 55, 158-161.

Raghu HB, Ashwin R, Ravi JE, Bagyaraj DJ. 2020a - Enhancing plant quality and out-planting growth of Acacia auriculiformis in dry wasteland plantations by inoculating selected microbial consortia in the nursery. Canadian Journal of Forest Research 50, 736-741.

Raghu HB, Ashwin R, Ravi JE, Bagyaraj DJ. 2020b - Performance of teak to selected microbial inoculants under large scale nursery trials and when planted in wasteland. Proceedings of National Academy of Sciences, India Section B Biological Sciences 90, 903-909.

Sanders ER. 2012 - Aseptic laboratory techniques: plating methods. Journal of Visualized Experiments 63, e3064.

Sukeerthi D, Nikhil N, Ashwin R, Bagyaraj DJ. 2020 - Microbial consortia promotes growth of Zinnia and Balsam seedlings raised in pro trays. Journal of Floriculture and Landscaping. 6, 4-8.

Thilagar G, Bagyaraj DJ, Hemlata C, Anshu BR, Ashwin R. 2014 - Synergistic effects of arbuscular mycorrhizal fungus Glomus mosseae and plant growth promoting bacterium Bacillus sonorensis on growth, nutrient uptake and yield of chilly. Journal of Soil Biology and Ecology. 34, 50-59.

Thilagar G, Bagyaraj DJ, Rao MS. 2016 - Selected microbial consortia developed for chilly reduces application of chemical fertilizers by $50 \%$ under field conditions. Scientia Horticulturae. 198, 27-35. 